\title{
HAND-ASSISTED RIGHT LAPAROSCOPIC NEPHRECTOMY IN LIVING DONOR
}

\author{
FERNANDO MEYER, LUIZ S. SANTOS, ANDRE E. VARASCHIN, ANDRESSA H. PATRIANI, \\ BRUNO F. PIMPAO
}

Cajuru University Hospital, Pontifical Catholic University, Curitiba, Parana, Brazil

\begin{abstract}
Objective: To assess results obtained with the authors' technique of right hand-assisted laparoscopic nephrectomy in living kidney donors.

Materials and Methods: We retrospectively analyzed 16 kidney donors who underwent handassisted right laparoscopic nephrectomy from February 2001 to July 2004. Among these patients, 7 were male and 9 were female, with mean age ranging between 22 and 58 years (mean 35.75).

Results: Surgical time ranged from 55 to 210 minutes (mean $127.81 \mathrm{~min}$ ) and warm ischemia time from 2 to 6 minutes (mean $3.78 \mathrm{~min}$ ) with mean intra-operative blood loss estimated at 90.62 $\mathrm{mL}$. There was no need for conversion in any case. Discharge from hospital occurred between the 3rd and 6th days (mean 3.81). On the graft assessment, immediate diuresis was seen in 15 cases (93.75\%) and serum creatinine on the 7th post-operative day was $1.60 \mathrm{mg} / \mathrm{dL}$ on average. Renal vein thrombosis occurred in 1 patient $(6.25 \%)$ who required graft removal, and lymphocele was seen in 1 recipient $(6.25 \%)$.

Conclusion: Hand-assisted right laparoscopic nephrectomy in living donors is a safe and effective alternative to open nephrectomy. Despite a greater technical difficulty, the procedure presented low postoperative morbidity providing good morphological and functional quality of the graft on the recipient.
\end{abstract}

Key words: kidney transplantation; nephrectomy; living donors; laparoscopy; graft survival Int Braz J Urol. 2005; 31: 17-21

\section{INTRODUCTION}

Laparoscopic nephrectomy has become routine for nephrectomy in a living donor, however the experience with techniques applied to the right kidney is quite limited (1).

The safety and benefits of laparoscopic nephrectomy for a living donor were first reported by Ratner et al. in 1995 with the objective of promoting a minimally invasive surgery with a quality that was equivalent to open surgery but esthetically better, featuring less postoperative pain and early rehabilitation
(2). In 2000, Jacobs et al., with the shortest warm ischemia time possible, achieved functional results equivalent to open techniques (3). With the laparoscopic nephrectomy, the number of transplanted kidneys derived from living donors increased significantly (15\% in Germany and 25\% in the United States) (4). Up to the present time, almost all these procedures are performed on the left side due to the longer length of the left renal vein (5).

The benefits of laparoscopic nephrectomy in a living donor have been well described, but limitations to the right laparoscopic nephrectomy have re- 
stricted this surgery to large centers only $(6,7)$. The right laparoscopic nephrectomy is technically more challenging when compared with the left side, especially due to the shorter length of the renal vein and the need for liver displacement $(8,9)$. Moreover, recent experiences are associated with a high index of venous thrombosis and consequent graft loss, thus most surgeons prefer the left laparoscopic nephrectomy $(8,10)$.

Some indications for performing the right nephrectomy are multiple renal arteries on the left side, moderate to severe ptosis of the right kidney and evidence of a better left kidney, following the principle of leaving the best kidney with the donor. It can occur with the presence of a cyst or a smaller kidney on the right side $(1,10)$.

The objective of this work is to analyze 16 patients and report the results obtained with the performance of hand-assisted right laparoscopic nephrectomy, considering surgical time, patients' gender and age, bleeding volume, need conversion to open surgery, employed technique and hospitalization time. The assessment of the graft in the recipient was performed through the presence or absence of immediate diuresis and serum creatinine on the 7 th post-transplantation day, in addition to the occurrence of clinical and surgical complications.

\section{MATERIALS AND METHODS}

This program of laparoscopic nephrectomy in a living donor started in February 2001. Donors underwent clinical and surgical assessment, in addition to tests such as excretory urography and renal arteriography for studying the vascular anatomy and collecting system.

The selection criteria were the existence of more than one left renal artery and a single right artery, a right renal cyst, women of fertile age intending future pregnancy since there is higher chance of pyelonephritis and hydronephrosis on the right side during the gestational period, as well as the presence of a peritoneal dialysis catheter on the right side due to the technical difficulty of implanting the graft resulting from the catheter (relative indication) on this side. Table- 1 shows the indications for right
Table 1 - Indications for performing right nephrectomy.

\begin{tabular}{lc}
\hline Two left renal arteries & 10 patients \\
Three left renal arteries & 1 patient \\
Women in fertile age & 3 patients \\
$\begin{array}{l}\text { Cyst in right kidney } \\
\text { Recipient with peritoneal dialysis } \\
\text { catheter on the right side }\end{array}$ & 1 patient \\
\hline
\end{tabular}

laparoscopic nephrectomy for each patient in this study.

We retrospectively analyzed 16 kidney donors undergoing hand-assisted right laparoscopic nephrectomy from February 2001 to July 2004. Among these, 7 were male and 9 female, with ages ranging from 22 to 58 years (mean 35.75 years).

\section{Surgical Technique}

The surgical procedure starts with the patient in partial left lateral decubitus (30 degrees) under general anesthesia and continuous peridural anesthesia. The transperitoneal access was used in all cases. The skin incision must be extended to the same size in centimeters as the size of the assistant surgeon's glove, for allowing the insertion of the device designed for introducing the hand. The incision begins at the lateral margin of the rectus muscle of the abdomen, $2 \mathrm{~cm}$ above the pubic symphysis, and is obliquely extended until the antero-superior iliac spine. The external oblique, internal oblique and transverse muscle of the abdomen are separated, the peritoneum is opened and the colon is displaced medially. The ureter is identified, isolated with a Penrose drain and dissected superiorly and inferiorly until it crosses the iliac vessels. Only then is the first 10-mm trocar (camera) introduced into the abdominal cavity through an incision made at the level of the umbilical scar, and guided by the surgeon's hand, which was introduced in the inguinal incision. The device that allows the hand to be introduced in the cavity is then installed according to the manufacturer's instructions.

In this sample, 3 devices were used for performing the procedure. In the first 3 cases we used

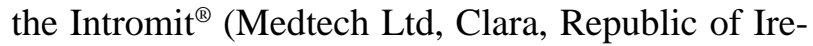


land), in the other 7 we used the Omniport ${ }^{\circledR}$ (Weck Closure Systems, Charlotte, NC, USA), and in the last 6 the Lap Disc ${ }^{\circledR}$ (Ethicon Endo-Surgery, Cincinnati, OH, USA). The use of 3 different devices was because when we started to perform the procedures, only the Intromit ${ }^{\circledR}$ was commercially available. Shortly after, we got the Omniport ${ }^{\circledR}$, a device that is easier to handle and which can be reused, leading to its use in 7 patients. Since the introduction of the Lap Disc $^{\circledR}$ on the market and its approval by the Health Ministry, we have started to use it. All devices were easy to install, promoting comfort and freedom for the surgeon when performing the required maneuvers during surgery.

The peritoneum was insufflated with $\mathrm{CO}_{2}$ and submitted to a $156-\mathrm{mmHg}$ tension, and the secondary ports were opened. A 5-mm trocar was placed in the direction of the hemiclavicular line approximately $3 \mathrm{~cm}$ below the right costal margin in order to withdraw the liver, and another 12-mm trocar was placed in the direction of the anterior axillary line below the iliac crest for inserting the scissors and the vascular clamp. If needed, a third accessory port can be established in the direction of the middle axillary line in order to assist in kidney presentation or to aspirate the cavity.

After introducing the hand and the trocars in the abdominal cavity, the kidney was dissected according to the technique of Nakada et al. (11). The harmonic scalpel Ultracision ${ }^{\circledR}$ (Ethicon Endo-surgery, Cincinnatti, OH, USA) was used in all procedures for dissection and coagulation of vessels and peritoneal structures. Once the dissection of the kidney, ureter and pedicle vessels had been completed, the renal artery was clamped with 3 proximal metallic clips and one distal clip, and immediately sectioned.

In the first case of this study, the renal vein was sectioned with a linear vascular stapler (EndoGIA $^{\circledR} 45 \mathrm{~mm} / 2.5 \mathrm{~mm}$ U.S. Surgical Corp., Norwalk, USA) and in the subsequent 5 cases we used a metallic clip associated with ligation using 2-0 cotton sutures. In the last 10 cases, we used the "hem-o-lok ${ }^{\circledR}$ " device (Weck Closure System, NC, USA).

The kidney was removed through the incision and the ureter was ligated at the level of the crossing of the iliac vessels. The hemostatic review was performed under direct visualization and a Penrose drain is inserted in the cavity by one of the orifices, and then removed after 24 hours. Finally, the synthesis of the muscular wall and skin was performed.

\section{RESULTS}

Surgical time ranged from 55 to 210 minutes (mean 127.81) and warm ischemia time from 2 to 6 minutes (mean $3.78 \mathrm{~min}$ ) with a mean intra-operative blood loss estimated at $90.62 \mathrm{~mL}$, ranging from 30 to $250 \mathrm{~mL}$. No case required conversion to open surgery. Discharge from hospital occurred between 3 and 6 days (mean 3.81). On the graft assessment, immediate diuresis was seen in 15 cases $(93.75 \%)$ and mean serum creatinine on the 7 th postoperative day was $1.60 \mathrm{mg} / \mathrm{dL}$ (0.8 to 6.4 ). Renal vein thrombosis occurred in 1 patient $(6.25 \%)$ requiring graft removal, and 1 recipient $(6.25 \%)$ had lymphocele. We did not observe urinary fistula. Dialysis was performed only in the patient who had renal vein thrombosis.

\section{COMMENTS}

In urology, minimally invasive surgery has established an important role in procedures of the upper urinary tract and more recently in prostate procedures. However, the most significant impact of the laparoscopic surgery is in renal transplantation. Among the 31 largest centers for renal transplantation in the United States on which $43 \%$ of all renal transplantations in that country are performed, 39\% of them used laparoscopic nephrectomy in 1998, and in 1999 the number of institutions increased to $65 \%$. In the same year, $21 \%$ of all surgeries were performed with the laparoscopic approach (12). We can certainly note a significant increase in the volume of living donors with the advent of laparoscopic surgery. Studies consistently reveal that there is decreased blood loss, reduced hospitalization time, early return to daily activities and a better cosmetic result (4).

With the improvement of surgical techniques, many studies have demonstrated higher safety for the donor and good graft function for the recipient $(3,13)$. Despite the left side being preferred in relation to the right side due to the length of the renal vein, there are 
indications for performing the surgery on the right side, such as multiple renal arteries on the left side, a cyst in the right kidney and an anomalous or smaller right kidney.

Lind et al. (14) performed right laparoscopic nephrectomies in living donors in 73 of 101 cases (72\%), with no differences in the number of thrombosis, graft loss and other complications when compared with the left kidney. Additionally, surgical time was statistically shorter for the right side. However, one graft was lost on the right side, the incidence of conversion to open surgery was higher (11\% vs. $8 \%)$ and there was a relatively higher decrease in graft function ( $32 \%$ vs. $23 \%)$.

After 300 pure laparoscopic nephrectomies with 44 performed on the right side, Abrahams et al. (1), stated that the right laparoscopic nephrectomy is safe for the donor, effective for the recipient and allows immediate and excellent functioning of the graft, in addition to the fact that there was no case of venous thrombosis. Also, they state that the liver position is not a drawback for performing the right laparoscopic nephrectomy, since the superior trocar allows a proper liver displacement and dissection of the renal pedicle. However, Turk et al. believe that the liver displacement represents a technical difficulty (15).

After performing pure right laparoscopic nephrectomy, and observing 38\% of venous thrombosis ( 3 of 8 cases) with consequent graft loss, Mandal et al. (10) suggested new approaches that could help in obtaining better results. Their suggestions, such as anastomosis of the renal vein with the saphenous vein and the performance of pre-operative three-dimensional tomography instead of arteriography, result in increased surgical time and costs. Gill et al. (16) reported success with retroperitoneal access in 5 cases, concluding that this access is feasible, however, a larger number of cases is required to confirm the study.

The hand-assisted right laparoscopic nephrectomy remains quite controversial due to the extension of the incision that must be made which would make the surgery lose its minimally invasive character, and also due to the cost of the device used for introducing the hand in the cavity. However, many centers have adopted this technique with quite satisfactory results. Buell et al. (17) state that the hand- assisted procedure is safer, since they observed 3 cases in $85(4 \%)$ of graft loss in pure laparoscopic nephrectomies and no cases in 40 hand-assisted nephrectomies.

\section{CONCLUSION}

The hand-assisted right laparoscopic nephrectomy in living donors is a safe method, especially since it helps in the liver displacement and kidney extraction, in addition to contributing to maintaining a proper length of the renal vein. Despite the higher technical difficulty, the procedure presented low postoperative morbidity in the donor and provided good morphological and functional quality of the graft in the recipient.

\section{REFERENCES}

1. Abrahams HM, Freise CE, Kang SM, Stoller ML, Meng MV: Technique, indications and outcomes of pure laparoscopic right donor nephrectomy. J Urol. 2004; 171: 1793-6.

2. Ratner LE, Ciseck LJ, Moore RG, Cigarroa FG, Kaufman HS, Kavoussi LR: Laparoscopy live donor nephrectomy. Transplantation. 1995; 60: 1047-9.

3. Jacobs SC, Cho E, Dunkin BJ, Flowers JL, Schweitzer $\mathrm{E}$, Cangro C, et al.: Laparoscopic live donor nephrectomy: the University of Maryland 3-year experience. J Urol. 2000; 164: 1494-9.

4. Kim FJ, Ratner LE, Kavoussi LR: Renal transplantation: laparoscopic live donor nephrectomy. Urol Clin North Am. 2000; 27: 777-85.

5. Kuo PC, Bartlett ST, Schweitzer EJ, Johnson LB, Lim JW, Dafoe DC: A technique for management of multiple renal arteries after laparoscopic donor nephrectomy. Transplantation. 1997; 64: 779-80.

6. Flowers JL, Jacobs S, Cho E, Morton A, Rosenberger WF, Evans D, et al.: Comparison of open and laparoscopic live donor nephrectomy. Ann Surg. 1997; 226: 483-9.

7. Slakey DP, Wood JC, Hender D, Thomas R, Cheng S: Laparoscopic living donor nephrectomy: advantages of the hand-assisted method. Transplantation. 1999; 68: 581-3.

8. Mandal AK, Kalligonis AN, Cohen C, Montgomery RA, Kavoussi LR, Ratner LE: Should the right kidney be used in laparoscopic live donor nephrectomy? Transplantation. 2000; 69: Abst \#116, S403. 
9. Arenas JD, Gupta M, Barnett K, Bollinger A, Holman RS, Halack N, et al.: Right nephrectomy is not a contraindication to laparoscopic donation. Transplantation. 2000; 69: Abst \#857, S335.

10. Mandal AK, Cohen C, Montgomery RA, Kavoussi LR, Ratner LE: Should the indications for laparoscopic live donor nephrectomy of the right kidney be the same as for the open procedure? Anomalous left renal vasculature is not a contra indication to laparoscopic left donor nephrectomy. Transplantation. 2001; 71: 660-4.

11. Nakada SY: Hand-assisted laparoscopic nephrectomy. J Endourol. 1999; 13: 9-15.

12. Finelli FC, Gongora E, Sasaki TM, Light JA: A survey: the prevalence of laparoscopic donor nephrectomy at large U.S. transplant centers. Transplantation. 2001; 71: 1862-4.

13. Ratner LE, Montgomery RA, Kavoussi LR: Laparoscopic live donor nephrectomy. A review of the first 5 years. Urol Clin North Am. 2001; 28: 709-19.

14. Lind MY, Hazebroek EJ, Hop WC, Weimar W, Jaap Bonjer H, Ijzermans JN: Right-sided laparoscopic live donor nephrectomy: is reluctance still justified? Transplantation. 2002; 74: 1045-8.

15. Turk IA, Deger S, Davis JW, Giesing M, Fabrizio MD, Schonberger B, et al.: Laparoscopic live donor right nephrectomy: a new technique with preservation of vascular length. J Urol. 2002; 167: 630-3.

16. Gill IS, Uzzo RG, Hobart MG, Streem SB, Goldfarb DA, Noble MJ: Laparoscopic retroperitoneal live donor right nephrectomy for purpose of allotransplantation and autotransplantation. J Urol. 2000; 164: 15004.

17. Buell JF, Hanaway MJ, Potter SR, Koffron A, Kuo PC, Leventhal J, et al.: Surgical techniques in right laparoscopic donor nephrectomy. J Am Coll Surg. 2002; 195: 131-7.

Received: September 23, 2004

Accepted after revision: November 30, 2004

\author{
Correspondence address: \\ Dr. Fernando Meyer \\ Serviço de Urologia, Hospital Universitário Cajuru \\ Av. Batel $1230 / 703$ \\ Curitiba, PR, 80420-090, Brazil \\ Fax: + 5541 3015-0303 \\ E-mail: fmeyer@onda.com.br
}

